\title{
Princípios e recomendações basilares para a comunicação dos dados de pesquisa
}

\author{
Michelli Costa \\ Doutoranda; Universidade de Brasília, Brasília, DF, Brasil; Universidade de Caxias do Sul, Caxias do \\ Sul, RS, Brasil; \\ michelli@unb.br \\ Fernando César Lima Leite \\ Doutor; Universidade de Brasília, Brasília, DF, Brasil; \\ fernandoc@unb.br
}

\begin{abstract}
Resumo: A comunicação de dados de pesquisa - que envolve aspectos da produção, compartilhamento e reutilização de dados - foi intensificada com a emergência do paradigma da ciência aberta. Nesse âmbito, surgiram diversos princípios e recomendações com o objetivo de nortear as discussões e as práticas relacionadas. $\mathrm{O}$ objetivo desse artigo é propor um conjunto basilar de princípios e recomendações para a comunicação de dados de pesquisa por meio da análise; tanto do desenvolvimento histórico de práticas quanto de políticas que têm norteado a discussão e iniciativas de comunicação dos dados de pesquisa. Adotaram-se como métodos a pesquisa bibliográfica e a pesquisa documental. A primeira foi a narrativa histórica de eventos, consubstanciada em uma linha do tempo. A segunda foi a análise comparativa de princípios e declarações identificadas por meio da pesquisa bibliográfica e pesquisa documental. Entre os resultados obtidos, foi possível propor o conjunto de princípios e recomendações basilares para comunicação de dados de pesquisa.
\end{abstract}

Palavras-chave: Compartilhamento de dados. Dados abertos. Dados de pesquisa.

\section{Introdução}

Nesse artigo, os processos de produção, compartilhamento e reutilização de dados de pesquisa são compreendidos a partir da ótica da comunicação científica. Garvey (1979) entende a comunicação científica como o conjunto de todas as atividades que englobam a produção, disseminação e uso da informação desde o início do processo de criação científica, o seu princípio, em que as ideias da pesquisa são geradas até o momento da aceitação dos resultados como parte do corpo de conhecimento científico. Os três grandes processos de 
comunicação da definição de Garvey (1979) - produção, disseminação e reutilização - são tomados como substrato teórico e adaptados para referir-se ao ciclo básico dos dados de pesquisa. Nesse sentido, adota-se a expressão 'comunicação de dados' em referência às práticas de produção, compartilhamento e reutilização de dados de pesquisa.

As discussões sobre a comunicação dos dados de pesquisa se intensificaram a partir da articulação do movimento internacional que visa o acesso aberto à informação científica. A perspectiva do acesso aberto tem por base uma "nova filosofia" iniciada nos anos 90, denominada por Costa (2006) como "filosofia aberta". Dentro dela, relacionam-se outras iniciativas, como os softwares livres e os arquivos abertos. A ampliação da noção de abertura e de democratização do acesso trazida por esta filosofia fez emergir um novo modo de pensar e de comunicar a ciência, que recebeu o nome de ciência aberta ou $e$ science. Nela, não são demandadas apenas as publicações científicas para o acesso público e irrestrito, mas é questionado todo o processo de produção da ciência. Leva-se em conta tanto os softwares utilizados para a pesquisa, em que predominam os softwares livres, quanto as metodologias de avaliação do alcance da pesquisa, nas quais discute-se o uso de métricas alternativas para a ciência. Neste escopo ampliado, a comunicação dos dados de pesquisa é apontada como uma das condições para avaliação dos resultados da pesquisa e para o desenvolvimento mais rápido, colaborativo e eficaz da ciência como um todo.

Apesar da centralidade da comunicação dos dados de pesquisa nas discussões sobre a ciência aberta, Guibault e Wiebe (2013) concluem que ainda não existe uma definição comum sobre o conceito 'dado de pesquisa'. Portanto, as autoras utilizam uma definição genérica que os consideram como aqueles dados que foram produzidos no decorrer da pesquisa. Por outro lado, a Organization for Economic Co-operation and Development (OECD) (2007) e Padilla Navarro et al. (2013) enfatizam que são os dados utilizados como fonte primária em uma pesquisa, e não necessariamente produzidos pela pesquisa. A concepção de Ribeiro et al. (2010) amplia o escopo e compreende que dados de pesquisa são aqueles que de algum modo foram utilizados na realização da 
pesquisa. Considerando os diferentes entendimentos apresentados, nesse artigo é adotada uma perspectiva ampla, que contempla as três visões, na qual dados de pesquisa são os dados produzidos e/ou utilizados para o desenvolvimento de uma pesquisa.

A variação de definições do conceito de dados de pesquisa está entre as causas mais imediatamente aparentes de divergências estruturais na expectativa e na prática da comunicação dos dados de pesquisa. A formalização das expectativas e a instrumentalização para as práticas são expressas em documentos com caráter de recomendação ou de política que buscam promover a comunicação dos dados de pesquisa. $\mathrm{O}$ aprofundamento da discussão acerca dos dados de pesquisa requer a identificação de um ponto comum nas recomendações ou políticas das principais iniciativas dessa natureza. O objetivo desse artigo é propor um conjunto basilar de princípios e recomendações para a comunicação de dados de pesquisa por meio da identificação e análise tanto do desenvolvimento histórico de práticas quanto de políticas que têm norteado a discussão e iniciativas de comunicação dos dados de pesquisa.

\section{Procedimentos metodológicos}

A investigação aqui relatada é de natureza exclusivamente descritiva e de abordagem qualitativa. Para o cumprimento do objetivo, adotaram-se como métodos a pesquisa bibliográfica e a pesquisa documental. A intenção foi obter tanto na literatura científica como em documentos de natureza institucional, dados que, ao serem analisados, revelassem o histórico das principais iniciativas de comunicação de dados bem como princípios e recomendações existentes até o presente momento. As buscas foram realizadas nas bases de dados Web of Science e Library and Information Science Abstracts (LISA) e também no Google Scholar. Para análise de dados foram adotadas duas estratégias. A primeira foi a narrativa histórica de eventos, consubstanciada em uma linha do tempo. A segunda foi a análise comparativa de princípios e declarações identificadas a partir da pesquisa bibliográfica e pesquisa documental. A partir dos resultados das análises histórica e comparativa, foi possível propor um 
conjunto de princípios e recomendações basilares para comunicação de dados de pesquisa.

\section{Um breve histórico sobre as principais iniciativas}

Apesar de o tema sobre a comunicação dos dados de pesquisa ter sobressaído recentemente nas discussões sobre comunicação científica e ciência aberta, sua prática não é nova. As primeiras tecnologias e serviços de informação para esta finalidade datam da década de 50, a partir da criação do World Data Centre (WDC). Para compreender seu desenvolvimento, realizou-se um levantamento histórico das principais iniciativas e princípios orientadores para a comunicação dos dados de pesquisa.

Para a narrativa histórica proposta, o WDC foi considerado a primeira iniciativa marcante consolidada com a finalidade de comunicação de dados de pesquisa. O WDC (WORLD..., [20--]) foi criado em 1957 para armazenar e dar acesso aos dados de um programa de pesquisa na área de geofísica. Inicialmente foram estabelecidos centros nos Estados Unidos, Europa, Japão e União Soviética. Desde então, segundo Ruttenberg e Rishbeth (1994), o sistema tem sido utilizado por projetos internacionais de diversas áreas do conhecimento, e já foram criados mais de 52 centros em 12 países.

Em 1971, a United Nations Educational, Scientific and Cultural Organization (UNESCO) publicou relatório de estudo sobre a viabilidade de um sistema de informação científica mundial, denominado United Nations International Scientific Information System (UNISIST). De acordo com Søndergaard et al. (2003), o modelo UNISIST ofereceu uma importante perspectiva sócio-técnica sobre as atividades de comunicação científica. Em suas palavras, o modelo chama a atenção para a comunicação da informação entre produtores e usuários de conhecimento, como um sistema constituído de diversas unidades organizacionais e documentárias, onde cada uma delas contribui para o compartilhamento de atividades na comunicação científica. $\mathrm{O}$ modelo UNISIST previa a interação entre produtores e usuários de informação científica e técnica por meio de diferentes canais de comunicação: os informais, 
os formais e os tabulares. Os dois primeiros referiam-se às interações pessoais e publicações/literatura científica, respectivamente.

Os canais tabulares, por sua vez, foram previstos no modelo UNISIST com a finalidade de comunicar dados técnicos e científicos por meio de unidades organizacionais, denominadas de centros de dados. Como descrito à época, a partir desses canais, os dados seriam apresentados em forma de tabelas ao contrário do fluxo linear do texto falado ou escrito das categorias anteriores. A despeito de muitos livros e artigos de periódicos incluírem dados tabulares em seus textos, estes frequentemente não acompanham a publicação. No entanto, à época, havia muitas razões que justificavam a operação com dados tabulares como fontes de informação de modo distinto das publicações impressas: a grande quantidade de levantamentos quantitativos sendo realizados resultou em uma acumulação de dados quantitativos; o reconhecimento de que a literatura não é o melhor canal de publicação para esse tipo de informação, sobretudo, ao se considerar os avanços tecnológicos em bancos de dados que facilitam sua recuperação e outras facilidades (UNITED NATIONS EDUCATIONAL, SCIENTIFIC AND CULTURAL ORGANIZATION, 1971; SØNDERGAARD et al., 2003). Os esforços da UNESCO representaram perspectiva visionária da necessidade de considerar dados de pesquisa no fluxo da comunicação da ciência. Por esta razão, a iniciativa possui grande relevância histórica.

$\mathrm{Na}$ década de 80 , deu-se início a uma discussão internacional a respeito da coleta e organização de dados sobre o ácido desoxirribonucleico, ou deoxyribonucleic acid (DNA). No fim da década, o governo norte-americano encomendou um planejamento do projeto para a execução do seu mapeamento. O Projeto Genoma Humano (PGH) iniciou em 1990 e contemplou a coleta de dados sobre o gene humano, métodos para o armazenamento dos dados e o desenvolvimento de ferramentas necessárias para analisá-los. A primeira fase do PGH foi desenvolvida com a participação de pesquisadores do Reino Unido, Alemanha, França, Japão e China, passando a ser gerido por uma instituição internacional. O PGH recebeu investimento de 3 bilhões de dólares e foi dado por concluído em 2003, dois anos antes do prazo previsto (FLÓRIA-SANTOS; NASCIMENTO, 2006). Segundo Zatz (2000, p. 47), o objetivo do PGH era 
“[...] identificar todos os genes responsáveis por nossas características normais e patológicas.”. A expectativa deste projeto foi, a partir dos genes mapeados, desenvolver vacinas de DNA, que teriam alta eficiência na cura de doenças. Zatz (2000, p. 47), que em 2000 era Coordenadora do Centro de Estudos do Genoma Humano, expectou que "[...] as vacinas de DNA poderão eliminar doenças como a tuberculose ou a Aids.”.

Em meados da década de 90, o U.S. Global Change Research Program (USGCRP) iniciou um debate público sobre o princípio do compartilhamento de dados de pesquisa. Com mandato presidencial, o Programa norte-americano foi iniciado na década de 90 para desenvolver pesquisas sobre as mudanças climáticas (RAND, 1995). Cerca de cinco anos após a criação do programa, a organização já estava convencida da necessidade do compartilhamento de dados para o sucesso dos estudos.

No início dos anos 2000, o National Institutes of Health (NIH), instituto de pesquisa norte-americano, estabeleceu sua política de comunicação dos dados de pesquisa. O NIH determinou, mediante política institucional, que todo o projeto de pesquisa financiada pela instituição, a partir de outubro de 2003, deveria ser acompanhado de planejamento para o compartilhamento dos dados de pesquisa. Em linhas gerais, a política determina que "Os dados devem estar disponíveis livremente o mais rápido possível, salvaguardando a privacidade dos participantes e protegendo dados confidenciais e proprietários." (NATIONAL INSTITUTES OF HEALTH, 2003, tradução nossa).

Em 2004, a OECD publicou o documento intitulado Declaration on Access to Research Data from Public Funding, que foi assinado por governos de 34 países. Na declaração, reafirma-se a importância da comunicação dos dados de pesquisa para o desenvolvimento da ciência e para aperfeiçoar os investimentos públicos em pesquisa científica (ORGANIZATION FOR ECONOMIC CO-OPERATION AND DEVELOPMENT, 2004). Além disso, são declarados dez princípios a serem seguidos pelos países signatários (Quadro 1). Neste documento, encontra-se presente o mesmo argumento incluído na política instituída pelo NIH: tornar públicos e acessíveis os dados resultantes de 
pesquisas financiadas como recursos públicos para ampliar o desenvolvimento científico e conferir transparência aos investimentos na pesquisa.

Quadro 1 - Princípios da declaração da OECD.

\begin{tabular}{|c|c|}
\hline Princípio & Definição \\
\hline Abertura & $\begin{array}{l}\text { Equilibrando os interesses de acesso aberto aos dados para aumentar a } \\
\text { qualidade e a eficiência da pesquisa e inovação, com a necessidade de } \\
\text { restrição de acesso em alguns casos para proteger os interesses sociais, } \\
\text { científicos e econômicos. }\end{array}$ \\
\hline Transparências & $\begin{array}{l}\text { Tornando a informação sobre as organizações de produtores de dados, } \\
\text { documentação que eles produzem e especificações das condições } \\
\text { associadas ao uso destes dados, disponíveis e acessíveis em nível } \\
\text { internacional. }\end{array}$ \\
\hline Conformidade legal & $\begin{array}{l}\text { Prestando a devida atenção à concepção de regimes de acesso para } \\
\text { dados de pesquisa, observando os requisitos legais nacionais em matéria } \\
\text { de segurança nacional, privacidade e segredo comerciais. }\end{array}$ \\
\hline $\begin{array}{l}\text { Responsabilidade } \\
\text { formal }\end{array}$ & $\begin{array}{l}\text { Promoção de regras institucionais explícitas, formais sobre as } \\
\text { responsabilidades das várias partes envolvidas em atividades } \\
\text { relacionadas a informações relativas à autoria, créditos de produção, da } \\
\text { propriedade, de restrições de uso, de disposições financeiras, de regras } \\
\text { éticas, de termos de licenciamento e de responsabilidade. }\end{array}$ \\
\hline Profissionalismo & $\begin{array}{l}\text { Elaboração de regras institucionais para a gestão dos dados da pesquisa } \\
\text { em ambiente digital, baseadas nas normas e valores profissionais } \\
\text { consagrados nos códigos de conduta das comunidades científicas } \\
\text { envolvidas. }\end{array}$ \\
\hline $\begin{array}{l}\text { Proteção da } \\
\text { propriedade } \\
\text { intelectual }\end{array}$ & $\begin{array}{l}\text { Descrevendo maneiras de obter acesso aberto no âmbito dos diferentes } \\
\text { regimes jurídicos de direito autoral ou outro direito de propriedade } \\
\text { intelectual aplicável às bases de dados, bem como segredos comerciais. }\end{array}$ \\
\hline Interoperabilidade & $\begin{array}{l}\text { Prestando a devida atenção aos requisitos de padrões internacionais } \\
\text { relevantes para o uso de várias formas, em cooperação com outras } \\
\text { organizações internacionais. }\end{array}$ \\
\hline $\begin{array}{l}\text { Qualidade e } \\
\text { segurança }\end{array}$ & $\begin{array}{l}\text { Descrevendo boas práticas para métodos, técnicas e instrumentos } \\
\text { utilizados na coleta, difusão e arquivamento de dados acessível para } \\
\text { permitir o controle de qualidade em análise pelos pares e outra forma de } \\
\text { preservar a autenticidade, originalidade, integridade, segurança e } \\
\text { estabelecer as responsabilidades. }\end{array}$ \\
\hline Eficiência & $\begin{array}{l}\text { Promoção de maior eficácia de custo dentro do sistema mundial da } \\
\text { ciência, descrevendo boas práticas de gestão de dados e serviços de } \\
\text { apoio especializados. }\end{array}$ \\
\hline Prestação de contas & $\begin{array}{l}\text { Avaliação do desempenho dos regimes de acesso de dados para } \\
\text { maximizar o apoio ao acesso aberto entre a comunidade científica e a } \\
\text { sociedade em geral. }\end{array}$ \\
\hline
\end{tabular}

Fonte: Adaptado de OECD (2004).

Três anos depois, em 2007, a OECD publicou seu segundo documento, denominado OECD Principles and Guidelines for Access to Research Data from Public Funding. O objetivo foi traçar amplo quadro de recomendações para as políticas científicas dos países membros, para que os dados resultantes de pesquisas financiadas com recursos públicos estejam amplamente disponíveis 
e não desrespeitem as políticas específicas de cada país. Quanto às singularidades regionais, o documento também declara que não pretende implicar obrigações para os países nem adicionar novos custos aos seus sistemas de produção de conhecimento científico (ORGANIZATION FOR ECONOMIC CO-OPERATION AND DEVELOPMENT, 2007). No novo documento, foram listados os dez princípios propostos em 2004 (Quadro 1) e modos de executálos. No entanto, nota-se que o princípio "Qualidade e Segurança" foi desmembrado em dois, um tratando apenas da qualidade e o outro da segurança. Além disso, foram acrescentados mais dois itens: Flexibilidade e Sustentabilidade (Quadro 2).

Quadro 2 - Novos princípios propostos pela OECD.

\begin{tabular}{ll}
\hline \multicolumn{1}{c}{ Princípio } & Quadro 2 - Novos princípios propostos pela OECD. \\
\hline Qualidade & $\begin{array}{l}\text { Este princípio é indicado como o elemento que conferirá possibilidade de } \\
\text { novos usos para os dados. Para tanto, o documento recomenda a } \\
\text { adequação a padrões internacionais de qualidade. No entanto, destaca que } \\
\text { estes padrões de qualidade não devem ser universais e devem respeitar as } \\
\text { especificidades de cada área do conhecimento. }\end{array}$ \\
Segurança & $\begin{array}{l}\text { Neste princípio, é mostrada a necessidade de suporte e instrumentos que } \\
\text { garantam a integridade, completude dos dados e ausência de erros. }\end{array}$ \\
Flexibilidade & $\begin{array}{l}\text { O princípio levanta a importância de considerar os avanços tecnológicos } \\
\text { que podem afetar o armazenamento e o acesso aos dados. Também aponta }\end{array}$ \\
a conformidade com os sistemas jurídicos e culturais de cada país \\
membro.
\end{tabular}
Fonte: Adaptado de OECD (2007).

Em 2009, criou-se um grupo de trabalho visando fortalecer ações direcionadas à comunicação de dados no contexto da ciência. O grupo, intitulado Work Grouping Open Data in Science (WGODS), foi articulado dentro da Open Knowledge Foundation (OKF), que tem por objetivo facilitar o acesso e uso de dados em vários contextos, inclusive na ciência. Seguindo os princípios da fundação, o grupo declarou ter por missão orientar e criar ferramentas que possibilitem o compartilhamento e a reutilização dos dados de pesquisa. De acordo com Molloy (2011), coordenadora do WGODS, apesar dos problemas culturais e da inércia ante a ciência aberta, renomadas agências de 
fomento à pesquisa têm requisitado planos para o compartilhamento dos dados como condição para a concessão de financiamento. Neste sentido, a autora destaca a iniciativa do NIH e da Wellcome Trust como fortes exemplos desta tendência.

A fim de oferecer suporte aos pesquisadores e possíveis usuários de dados compartilhados, o grupo desenvolveu a ferramenta denominada It is open data? (OPEN KNOWLEDGE FOUNDATION, [20--]). Segundo sua própria apresentação, a ferramenta visa disponibilizar informações sobre a abertura dos dados, em especial os dados de pesquisa. O sistema considera como dados de pesquisa todos os dados primários relacionados a uma publicação científica revisada pelos pares (paper). Além dessa ferramenta, o WGODS sistematizou um conjunto de condições que define a abertura do acesso e do uso dos dados (Quadro 3).

Quadro 3 - Condições de abertura dos dados propostos pelo WGODS.

\begin{tabular}{l} 
Quadro 3 - Condições de abertura dos dados propostos pelo WGODS. \\
\hline 1. É livre para uso e reuso. \\
2. É distribuído sem restrições \\
3. Utiliza a licença que determina que dados derivados compartilhem a \\
mesma licença de abertura. \\
4. É disponível em todo seu conjunto. \\
5. Quando possuir custo de reprodução, este deve ser razoável. \\
6. Preferencialmente deve ser apto para o acesso por meio da Internet e \\
sem custos. \\
7. É disponível em formato conveniente e modificável. \\
Fonte: Adaptado de Molloy (2011).
\end{tabular}

As condições determinadas pelo grupo foram baseadas na definição de dados abertos da OKF e do Protocol for Implementing Open Access Data (SCIENCE..., [20--]). Molloy (2011) justifica que a definição de abertura para os dados foi necessária dentro da perspectiva da ciência aberta porque se considerou que a noção aplicada às publicações científicas pelo Movimento de Acesso Aberto não produzia uma liberdade de acesso ao conhecimento. A autora defende que a ideia de "acesso aberto" (free access ou open access) está relacionada à perspectiva de acesso gratuito, e não aberto, como almejam o grupo e seus parceiros. Molloy (2011) defende seu argumento com base em 
dados dos periódicos científicos de acesso aberto cadastrados no Directory of Open Access Journals (DOAJ). Segundo a autora, apenas 22\% dos periódicos cadastrados no DOAJ utilizam as licenças Creative Commons, e deste conjunto alguns periódicos ainda contêm restrições quanto ao uso comercial e não demandam que obras derivadas compartilhem da mesma licença. Desse modo, apenas uma reduzida parte dos periódicos classificados como de acesso aberto promovem, de fato, o conhecimento aberto.

Diante da problemática apresentado pelo WGODS, Molloy (2011) observa que se fez necessária a criação de um conjunto de princípios para a comunicação dos dados de pesquisa. O novo conjunto de princípios, intitulado Panton Principles: Principles for Open Data in Science, foi elaborado por quatro pesquisadores, três do Reino Unido e um dos Estados Unidos, e é assinado por mais de 265 pesquisadores ${ }^{1}$ de todo o mundo. O documento parte da ideia geral de que a ciência é baseada na reutilização e discussão do conhecimento científico já publicado, e que este processo é mais efetivo se os dados das pesquisas publicadas estiverem abertos, ressaltando assim os princípios da ciência moderna. Para a autora, a abertura dos dados significa a disponibilização livre na Internet com permissões para download, cópia, análise, reprocessamento e uso em software. Além disso, deve ser assegurado que os dados precisam ser disponibilizados em local de domínio público. Após a definição de contexto e de conceitos, são propostos quatro princípios para a abertura dos dados de pesquisa (Quadro 4).

Quadro 4 - Princípios declarados no Panton Principles.

\section{Princípios}

1. Os dados devem ser acompanhados de uma declaração clara e explícita sobre suas permissões de uso. Esta declaração precisa ser clara, irrevogável e baseada em norma jurídica apropriada.

2. As permissões de uso devem ser declaradas por meio de licença adequada.

3. Utilização da definição de dados proposta pela Open Knowledge não limita o uso comercial dos dados e outras restrições de uso.

4. A permissão do uso dos dados, principalmente daqueles financiados com recurso público, deve ser feita com licenças de domínio público, tais como a PDDL ou CCO (apresentadas a seguir). 
Nos princípios enunciados sobressai a preocupação com o licenciamento dos dados de pesquisa para o contexto da ciência aberta. De acordo com os Panton Principles, apesar da proximidade com a filosofia e princípios do software livre, para o contexto de dados de pesquisa é desencorajado o uso das mesmas licenças utilizadas pelos softwares, tais como a Free Documentation License (GFDL), a GNU General Public License (GPL) e a Berkeley Software Distribution (BSD). Para a adequação da licença e da definição de dados proposta pela Open Knowledge no contexto da ciência aberta, o documento traz uma lista de seis licenças adequadas à comunicação de dados de pesquisa (Quadro 5).

Quadro 5 - Licenças recomendadas pelo Panton Principles.

$$
\text { Licenças }
$$

Domínio

BY* SA**

Creative Commons CC Zero (CC0)

Open Data Commons Public Domain Dedication and

Conteúdo e dados

Dados

$\mathrm{N}$

Licence (PDDL)

Creative Commons Attribution 4.0 (CC-BY-4.0) Conteúdo e dados $\quad \mathrm{S} \quad \mathrm{N}$

Open Data Commons Attribution License (ODC-BY) $\quad$ Dados $\quad$ S $\quad$ N

Creative Commons Attribution Share-Alike 4.0 (CC-BY- Conteúdo e dados S S S

SA-4.0)

Open Data Commons Open Database License (ODbL) $\quad$ Dados $\quad$ S $\quad$ S

Fonte: Adaptado de Open Definition (OPEN KNOWLEDGE INTERNATIONAL, [2016]).

*BY - A licença requer atribuição de autoria.

**SA - Produtos derivados dos dados cobertos pela licença deverão compartilhar da mesma licença.

Sobre o conjunto de licenças, é importante ressaltar três características; A primeira trata do amplo reuso das licenças, uma vez que elas não são especificadas por organização ou jurisdição. A segunda é acerca das aproximações da licença com outras da mesma natureza, tais como as utilizadas pelos softwares livres. A terceira aborda a atualização e as recomendações direcionadas para as licenças por projetos que objetivam compartilhar seus dados.

No mesmo ano da publicação dos Panton Principles, foi criado um novo grupo de trabalho nomeado Publishing Open Data. De acordo com Hrynaszkiewicz e Cockerill (2012), o grupo foi articulado pelos editores da BioMed Central para abrir um canal de discussão com outros editores 
acadêmicos sobre o compartilhamento de dados das pesquisas publicadas por seus periódicos. Como resultado desta articulação, em 2011 foi publicada uma política intitulada Join Data Archiving Policy. No documento são descritos os requisitos para a publicação de dados em artigos acadêmicos em várias áreas do conhecimento. Adicionalmente, são apontados os elementos que uma política editorial deve abarcar para requerer o compartilhamento dos dados das pesquisas que publicam. A política também destaca o Dryad Digital Repository (2016), que armazena dados de pesquisas na área de ciências da saúde.

Ainda em 2011, os Research Councils United Kingdom (RCUK) ${ }^{2}$ publicaram um novo conjunto de princípios para a comunicação de dados de pesquisa, o RCUK Common Principles on Data Policy (Quadro 6). De acordo com Corti et al. (2014), tal política representou grande avanço na promoção do compartilhamento de dados de pesquisa, uma vez que o RCUK é responsável pelo financiamento de $55 \%$ das pesquisas da região e influenciou o comportamento de outras instituições fora de seu domínio.

Quadro 6 - Princípios para o compartilhamento e reutilização dos dados de pesquisa da RCUK. Princípio

1. Dados de pesquisa resultantes de financiamento público são um bem público, produzido para o interesse público. Assim, devem ser disponibilizados abertamente, com o menor número de restrições possível, de forma oportuna e responsável.

2. Políticas e planos de gerenciamento de dados institucionais e projetos específicos devem estar em conformidade com as normas e melhores práticas da sua comunidade científica. Dados com valor de longo prazo devem ser preservados e permanecerão acessíveis e utilizáveis para as pesquisas futuras.

3. Para permitir que os dados da pesquisa sejam detectáveis e efetivamente reutilizados por outras pesquisas, seus metadados devem ser registrados de maneira adequada e abertamente disponíveis para permitir que outros pesquisadores compreendam o potencial dos dados de pesquisa e as possibilidades de reuso. Os resultados publicados devem sempre incluir informações sobre como acessar os dados de apoio.

4. RCUK reconhece que há restrições legais, éticas e comerciais sobre o acesso aos dados de pesquisa. Para garantir que o processo de pesquisa não seja prejudicado pelo lançamento inadequado de dados, políticas e práticas de organização de pesquisa devem garantir que estas restrições sejam consideradas em todas as fases do processo de pesquisa.

5. Para assegurar que as equipes de pesquisa obtenham o reconhecimento apropriado para o esforço envolvido na obtenção e análise de dados, poderá ser dado o direito a um período limitado de utilização privilegiada dos dados que foram coletados para capacitá-los a publicar os resultados de sua pesquisa. A duração deste período variará de acordo com a disciplina de investigação e, se for caso, será analisado nas políticas publicadas pelos Conselhos de Pesquisa.

6. A fim de reconhecer as contribuições intelectuais dos pesquisadores que geram, 
preservam e compartilham conjuntos de dados de pesquisa, todos os usuários de dados da pesquisa devem reconhecer as fontes de seus dados e respeitar os termos e condições sob as quais são acessados.

7. É conveniente utilizar recursos públicos para apoiar a gestão e partilha de dados da pesquisa financiada publicamente. Para maximizar o benefício de pesquisa, que pode ser adquirida a partir de orçamentos limitados, os mecanismos para estas atividades devem ser eficientes e com utilização de recursos públicos rentáveis. Fonte: RCUK (2011).

Segundo Corti et al. (2014), até 2014, onze instituições de pesquisas já haviam instituído suas políticas de comunicação de dados de pesquisa, baseadas nos princípios propostos pelo RCUK. As políticas determinam que um plano para o compartilhamento dos dados resultantes da pesquisa deve ser entregue junto com a proposta da pesquisa. Assim, o planejamento para a comunicação dos dados da pesquisa faz parte do próprio planejamento da pesquisa. Para viabilizar o planejamento, é oferecido aos pesquisadores um conjunto de serviços de suporte e infraestrutura. Corti et al. (2014) destacaram cinco deles:

a) UK Data Service do Economic and Social Research Council (ESRC) (UK..., c2016);

b) Rede de dados do Natural Environment Research Council (NERC) (NATURAL..., c2016);

c) MRC Data Support Service do Medical Research Council (MRC) (MEDICAL..., c2016);

d) Atlas Petabyte Storage do Science and Technology Facilities Council (STFC) (SCIENTIFIC..., c2016);

e) Archeology Data Service do Arts and Humanities Research Council (AHRC) (ARCHEOLOGY..., [20--]).

Basicamente, todos os serviços disponibilizam orientações para a gestão e compartilhamento dos dados e oferecem suporte para a sua curadoria, preservação e disseminação nas áreas do conhecimento em que estão inseridos.

No contexto europeu, destaca-se o programa Horizon 2020 para promoção do compartilhamento e reutilização de dados de pesquisa. O programa tem por objetivo aperfeiçoar os investimentos da União Europeia em pesquisa e inovação. Para tanto, busca promover mais acesso e com mais rapidez aos 
resultados de pesquisa que financia. Os resultados devem ser expostos em publicação científica e dados de pesquisa. No conjunto das publicações científicas, são abrangidos os documentos revisados pelos pares, tais como artigos de periódicos, e os não revisados, como os livros e relatórios de pesquisa. Já os dados de pesquisa

[...] referem-se às informações, em particular fatos ou números, coletados para serem examinados e considerados e como base para discussão ou cálculo. No contexto da pesquisa, exemplos de dados incluem estatísticas, resultados de experimentos, medidas, observações resultantes do campo de trabalho, resultados de questionários, gravações de entrevistas e imagens. O foco é os dados de pesquisa que estão disponíveis em formato digital. ( EUROPEAN COMMISSION, 2013, p. 3).

No âmbito do Horizon 2020, o acesso aberto aos dados de pesquisa é definido como o direito de acesso e reutilização dos dados sob os termos e condições do Grant Agreement ${ }^{3}$. As condições estabelecidas pelo documento determinam que os beneficiários de recursos da União Europeia devem depositar seus dados de pesquisa em repositórios de dados apropriados, permitindo o seu acesso, mineração, exploração, reprodução e compartilhamento, sem custo para os usuários. No documento, declara-se a expectativa de que os dados de pesquisa sirvam como um objeto de validação dos resultados de pesquisa que foram ou serão publicados. Como condição para o depósito também se determina que o conjunto de dados deva ser estruturado de forma padronizada e seus metadados devem incluir os seguintes elementos:

a) os termos European Union (EU) e Horizon 2020;

b) o nome do projeto financiado e seu número de controle;

c) a data da publicação, o período de embargo, quando aplicável, e o identificador persistente (EUROPEAN COMMISSION, 2015).

Para o cumprimento dos requisitos, é necessário elaborar um plano de gestão dos dados. De acordo com o documento,

[...] plano de gestão é um documento que esboça como o dado de pesquisa coletado ou gerado será manipulado durante um projeto de pesquisa, e depois dele completo, descreve quais dados serão coletados/gerados, seguindo qual metodologia e padrões, se e como esse dado será compartilhado e/ou será aberto para o acesso, e como será 
curado e preservado. (EUROPEAN COMMISSION, 2013, p. $10)$.

Apesar das exigências apontadas, são consideradas as possibilidades de exceção, ou seja, aquelas pesquisas que não terão seus dados disponibilizados em acesso aberto. As pesquisas que se enquadram nesta categoria são aquelas cujos resultados são passíveis de patenteamento ou por algum outro motivo que requeira proteção dos dados.

O início do ano de 2016 foi marcado pela ampla discussão que o tema do compartilhamento de dados de pesquisa recebeu em nível internacional. A visibilidade para o assunto decorreu do acordo de cooperação internacional denominado Statement on Data Sharing in Public Health Emergencies, que explicitou a necessidade do compartilhamento de dados de pesquisa para a superação de epidemias como o Zika Vírus e o Ebola. O documento foi assinado por 33 instituições, entre orgãos internacionais, ONGs, institutos de pesquisas e grandes editores científicos (Quadro 7).

Quadro 7 - Instituições aderentes ao acordo de cooperação internacional.

\begin{tabular}{|ll|}
\hline 1. & Academy of Medical Sciences, UK \\
2. & Bill and Melinda Gates Foundation \\
3. & Biotechnology and Biological Sciences Research Council (BBSRC) \\
4. & The BMJ \\
5. & Bulletin of the World Health Organization \\
6. & Canadian Institutes of Health Research \\
7. & The Centers for Disease Control and Prevention \\
8. & Chinese Academy of Sciences \\
9. & Chinese Centre for Disease Control and Prevention \\
10. & The Department of Biotechnology, Government of India \\
11. & The Department for International Development (DFID) \\
12. & Deutsche Forschungsgemeinschaft (DFG) \\
13. & eLife \\
14. & The Economic and Social Research Council (ESRC) \\
15. & F1000 \\
16. & Fondation Mérieux \\
17. & Fundação Oswaldo Cruz (Fiocruz) \\
18. & The Institut Pasteur \\
19. & Japan Agency for Medical Research and Development (AMED) \\
20. & The JAMA Network \\
21. & The Lancet \\
22. & Médecins Sans Frontières/Doctors Without Borders (MSF) \\
23. & National Academy of Medicine \\
24. & National Institutes of Health, USA \\
25. & National Science Foundation, USA \\
26. & The New England Journal of Medicine (NEJM) \\
27. & PLOS \\
\hline
\end{tabular}




\begin{tabular}{ll|}
28. & Science Journals \\
29. & South African Medical Research Council \\
30. & Springer Nature \\
31. & UK Medical Research Council \\
32. & Wellcome Trust \\
33. & ZonMw - The Netherlands Organisation for Health Research and Development \\
\hline
\end{tabular}
Fonte: (STATEMENT..., 2016).

O objetivo declarado no acordo é garantir que qualquer informação com algum valor para o combate ao Zika Vírus seja disponibilizada de modo rápido e gratuito. Além das doenças causadas pelo Zika Vírus, o acordo realça que a prática permitirá responder com mais agilidade às futuras emergências da saúde pública. No acordo, são destacados dois compromissos assumidos pelos signatários; o primeiro para o grupo dos editores científicos e o segundo para as instituições fomentadoras de pesquisa na área das ciências da saúde. O primeiro compromisso, assumido pelos editores científicos, é a disponibilização das publicações científicas e seus dados de pesquisa de forma rápida e aberta. Adicionalmente, estabeleceu-se acordo com os editores que as pesquisas que tivessem seus dados ou preprints disponibilizados antes da publicação do artigo não tenham sua submissão comprometida. O segundo compromisso, assumido pelas agências financiadoras de pesquisa, refere-se ao comprometimento em promover pesquisas relevantes para o tema das doenças emergentes e definir mecanismos que garantam a comunicação dos seus dados o mais rapidamente possível. O documento finaliza convidando outras instituições a aderirem ao acordo, e disponibiliza na própria página web um formulário para interessados tornarem-se signatários.

Todos os eventos que foram marcados nesta seção estão ilustrados na Figura 1, no formato de linha do tempo ${ }^{4}$. 
Figura 1 - Linha do tempo da promoção da abertura dos dados de pesquisa.

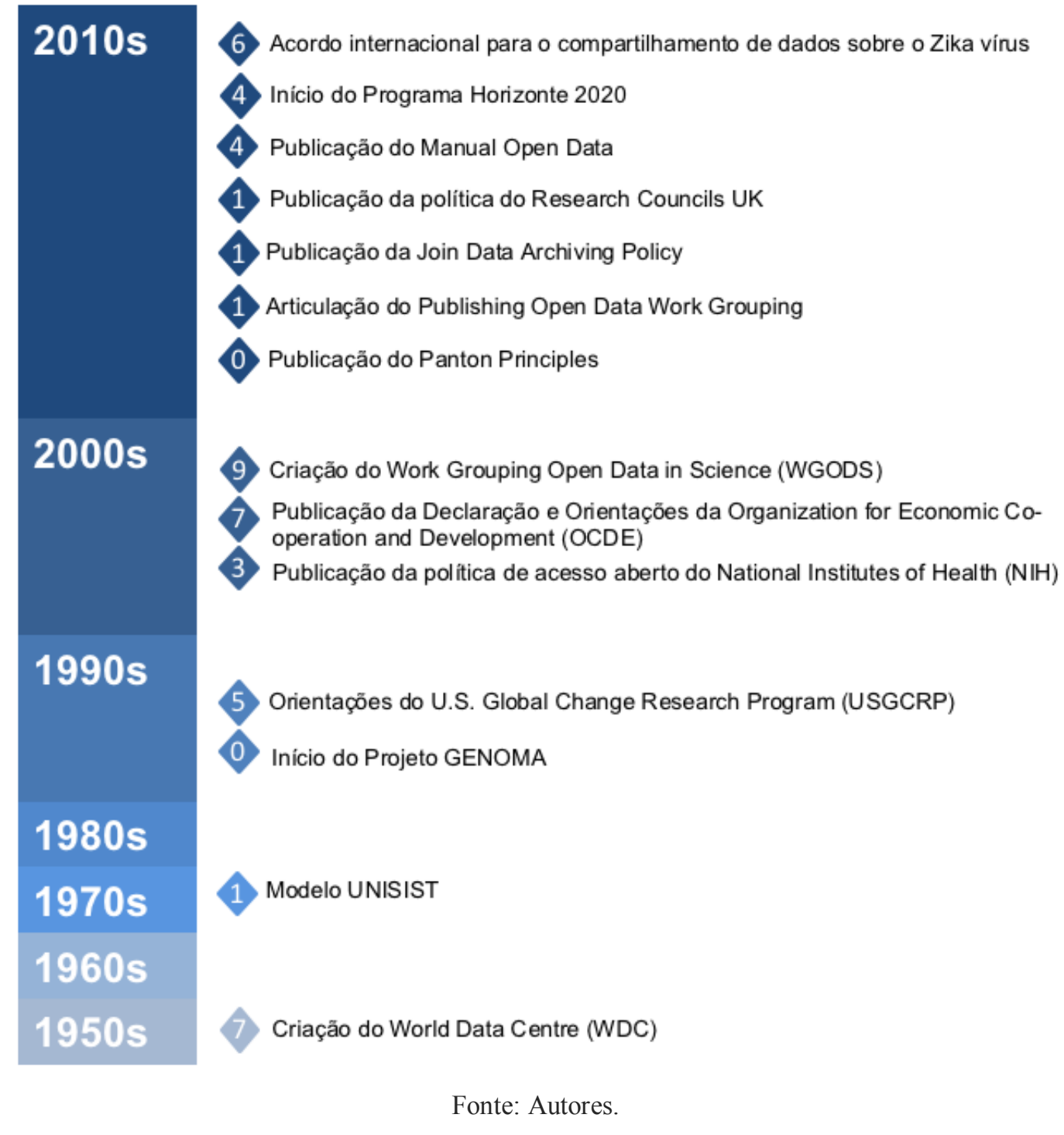

4 Princípios e recomendações basilares para o compartilhamento e reutilização de dados de pesquisa

O breve histórico delineado anteriormente discutiu cinco documentos que apontam princípios e recomendações para a comunicação de dados de pesquisa. Nessa seção será apresentada uma síntese dos cinco documentos, com vistas à proposição de um conjunto de princípios basilares acordados entre diversos países e instituições que já se dedicaram à discussão sobre o tema.

No nível regional, a Europa predomina sobre as demais regiões em quantidade de iniciativas e adesão às declarações de princípios para a 
comunicação dos dados de pesquisa. Já os Estados Unidos não se destacam em relação à quantidade de declarações internacionais, mas chama a atenção pela quantidade e a qualidade de iniciativas desenvolvidas localmente, em especial, na área das ciências da saúde. Na América Latina observou-se a participação de apenas dois países, o Brasil e o México. A inserção brasileira deu-se pelo envolvimento de uma pesquisadora à articulação WGODS e pela adesão da Fundação Oswaldo Cruz (Fiocruz) ao acordo de cooperação internacional Statement on Data Sharing in Public Health Emergencies. Nenhuma outra iniciativa brasileira foi identificada a partir do recorte definido neste artigo. A articulação do grupo WGODS também contou com a participação de pesquisadores de alguns países da Ásia e da Nova Zelândia. Já a adesão mexicana esteve relacionada à aderência da declaração da OECD, que além de abranger países da América do Norte e Europa, também incluíram a África do Sul, a China, o Japão e a Coreia do Sul.

Em termos gerais, foi possível identificar 14 princípios declarados nos documentos analisados como valores relevantes e basilares para o contexto da comunicação dos dados de pesquisa. Todos os quadros-resumos das declarações discutidas na seção anterior foram sistematicamente organizados no Quadro 8, a fim de comparar as propostas dos cinco documentos.

Quadro 8 - Princípios e recomendações discutidos nas declarações analisadas.

\begin{tabular}{|c|c|c|c|c|c|c|}
\hline Princípios e recomendações & OECD & WGODS & $\mathbf{P P}^{5}$ & RCUK & H2020 & Total \\
\hline Responsabilidade formal & 1 & 1 & 1 & 1 & 1 & 5 \\
\hline Conformidade legal & 1 & 0 & 1 & 1 & 1 & 4 \\
\hline $\begin{array}{l}\text { Interoperabilidade e qualidade dos } \\
\text { dados }\end{array}$ & 1 & 0 & 1 & 1 & 1 & 4 \\
\hline Equilíbrio de interesses & 1 & 0 & 0 & 1 & 1 & 3 \\
\hline Proteção da propriedade intelectual & 1 & 0 & 0 & 1 & 1 & 3 \\
\hline Preservação & 1 & 0 & 0 & 1 & 1 & 3 \\
\hline $\begin{array}{l}\text { Custo mínimo para a reprodução dos } \\
\text { dados }\end{array}$ & 1 & 1 & 0 & 0 & 1 & 3 \\
\hline Transparência para a ciência & 1 & 0 & 0 & 0 & 1 & 2 \\
\hline Prestação de contas & 1 & 0 & 0 & 0 & 1 & 2 \\
\hline Profissionalismo & 1 & 0 & 0 & 0 & 0 & 1 \\
\hline Sem restrição de uso & 0 & 1 & 0 & 0 & 0 & 1 \\
\hline Conjunto de dados & 0 & 1 & 0 & 0 & 0 & 1 \\
\hline Compartilhamento da mesma licença & 0 & 1 & 0 & 0 & 0 & 1 \\
\hline Dados em formato modificável & 0 & 1 & 0 & 0 & 0 & 1 \\
\hline Total & 10 & 6 & 3 & 6 & 9 & $\mathrm{x}$ \\
\hline
\end{tabular}


Após a comparação, observou-se que apenas um dos 14 princípios foi declaradamente comum aos cinco documentos. Outros dois foram aventados em quase todos os documentos, exceto o WGODS. Em relação à maioria dos princípios, notou-se a predominância dos seguintes documentos: declarações da OECD, política do RCUK e política do H2020. Os itens tratados nos Panton Principles obtiveram menor ocorrência dentro do conjunto de princípios e recomendações observados, mas quando presentes, acompanharam a tendência do grupo descrito anteriormente. O documento publicado pelo WGODS destacou-se por incluir princípios singulares aos outros documentos (Gráfico 1).

Gráfico 1 - Comparação dos princípios e recomendações discutidos nas declarações analisadas.

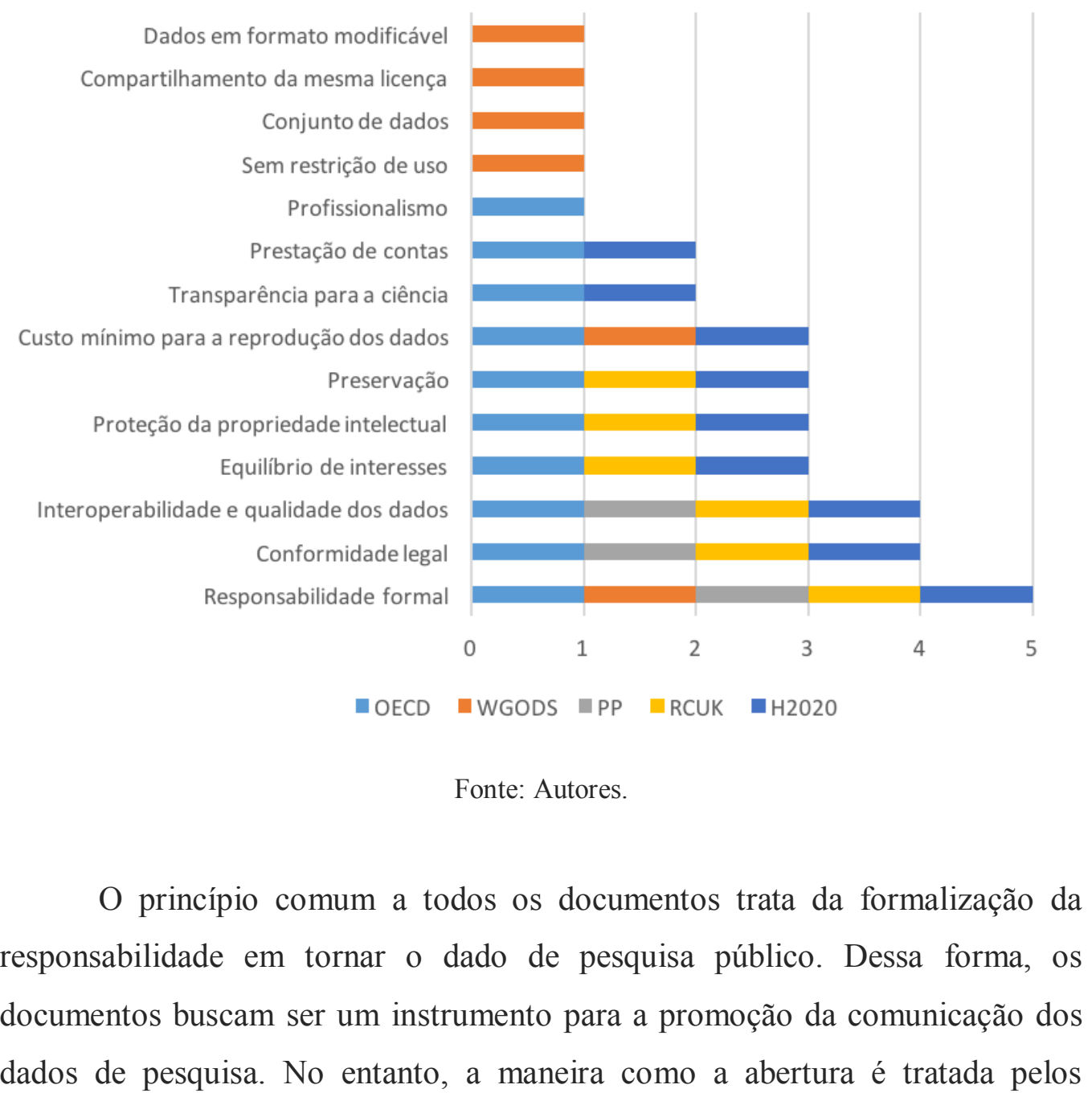


documentos varia significativamente. Na declaração da OECD, é indicado o uso de regras institucionais que determinem as possíveis restrições de uso e os termos de licenciamento, entre outros aspectos. Já no documento do WGODS, é definido que o compartilhamento e reutilização de dados de pesquisa dentro do contexto da ciência aberta não devem estipular restrições de uso e devem se utilizar de licenças internacionais adequadas para esta finalidade. De modo geral, essa variação marca a discrepância entre os princípios e recomendações contidos nos documentos analisados.

A declaração da OECD, a política do RCUK e o programa H2020 revelam tendências para mediação de interesses diversos relacionados aos resultados das pesquisas, considerando até mesmo atender restrições de acesso e reuso com vistas a interesses particulares, sejam eles comerciais ou de direito de propriedade intelectual. Já o documento do WGODS preza pela completa abertura do acesso e reutilização dos dados de pesquisa, sem nenhuma restrição. Fundamentalmente, os princípios que divergem são os relacionados ao "equilíbrio de interesses" e à "proteção da propriedade intelectual", os quais se opõem à "promoção do acesso e do uso sem restrições".

Apesar das diferenças apontadas, foi possível propor um conjunto de princípios e recomendações que compõem o quadro das discussões sobre a comunicação dos dados de pesquisa em nível internacional (Quadro 9). O conjunto tem o potencial de representar a base para investigações sobre o tema.

Quadro 9 - Conjunto dos princípios e recomendações para a comunicação dos dados de pesquisa.

\begin{tabular}{|c|c|c|}
\hline \multicolumn{3}{|c|}{ Princípios e recomendações } \\
\hline 1 & Responsabilidade formal & $\begin{array}{l}\text { Formalização do compromisso em tornar o dado de pesquisa } \\
\text { público. }\end{array}$ \\
\hline 2 & Conformidade legal & $\begin{array}{l}\text { Destaca que o a obrigatoriedade do compartilhamento e } \\
\text { reuso de dados de pesquisa deve ser flexível aos sistemas } \\
\text { jurídicos do país ou região. }\end{array}$ \\
\hline 3 & $\begin{array}{l}\text { Interoperabilidade e } \\
\text { qualidade dos dados }\end{array}$ & $\begin{array}{l}\text { Evidencia a necessidade de padrões internacionais para a } \\
\text { descrição e armazenamento e recuperação dos dados. }\end{array}$ \\
\hline 4 & Equilíbrio de interesses & $\begin{array}{l}\text { Considera exceções na obrigatoriedade do compartilhamento } \\
\text { dos dados de pesquisa em função de interesses dos } \\
\text { pesquisadores e financiadores. }\end{array}$ \\
\hline 5 & $\begin{array}{l}\text { Proteção da propriedade } \\
\text { intelectual }\end{array}$ & $\begin{array}{l}\text { Considera a possibilidade de restrição ao compartilhamento } \\
\text { e reuso dos dados de pesquisa em função dos direitos de } \\
\text { propriedade intelectual e de segredos comerciais. }\end{array}$ \\
\hline 6 & Custo mínimo para a & Determina que o acesso e o uso do dado de pesquisa gerem o \\
\hline
\end{tabular}


reprodução dos dados

7 Transparência para a ciência

8 Prestação de contas mínimo de custo possível para o usuário.

Destaca a importância do acesso aos dados de pesquisa para tornar os resultados apresentados incorruptíveis e refutáveis.

Disponibilização dos dados de pesquisa como forma de comprovar a realização da pesquisa e o cumprimento de seus objetivos.

\begin{tabular}{lll}
9 Sem restrição de uso & $\begin{array}{l}\text { Recomenda que não seja atribuída nenhuma restrição de uso, } \\
\text { nem mesmo de uso comercial. }\end{array}$ \\
$\mathbf{1 0}$ Conjunto de dados & $\begin{array}{l}\text { Requisição para todo o conjunto de dados produzidos e/ou } \\
\text { utilizados pela pesquisa para a comprovação dos seus } \\
\text { resultados. }\end{array}$ \\
$\mathbf{1 1}$ Preservação & $\begin{array}{l}\text { Necessidade de evidenciar formas e financiamentos para a } \\
\text { preservação dos dados em longo prazo. }\end{array}$ \\
$\mathbf{1 2}$ Profissionalismo & $\begin{array}{l}\text { Uso de valores e técnicas profissionais para o tratamento, } \\
\text { armazenamento e disponibilização dos dados de pesquisa. }\end{array}$ \\
mesma licença & $\begin{array}{l}\text { Implicação da necessidade de obras derivadas, ou que } \\
\text { utilizem os dados de pesquisa, compartilhem da mesma } \\
\text { licença que garante a abertura dos dados. }\end{array}$ \\
$\mathbf{1 4}$ Dados em formato & $\begin{array}{l}\text { Indica que, sempre que possível, os dados de pesquisa } \\
\text { devem ser compartilhados em formato modificável. }\end{array}$ \\
\hline
\end{tabular}

\section{Considerações finais}

Inseridos no contexto da comunicação científica, os processos de produção, compartilhamento e reutilização de dados de pesquisa - entendidos como comunicação de dados de pesquisa - têm cada vez mais objeto de investigação em diversas áreas, mas sobretudo na ciência da informação. Nesse âmbito, o tópico tem sido responsável por apontar a necessidade se compreender que a produção do conhecimento científico tanto depende quanto gera dados de pesquisa, além dos resultados de pesquisa materializados em publicações científicas, ambos igualmente relevantes para a aceleração das descobertas e avanço da ciência.

Como observado ao longo do artigo, as práticas relacionadas com a comunicação de dados de pesquisa têm sido norteadas por princípios e recomendações diversas cujos teores tentam englobar pressupostos do acesso aberto, entretanto, principalmente pressupostos da ciência aberta. Nesse sentido, tentam constituir uma teia de requisitos que vão além da ideia da gratuidade de acesso, comum ao acesso aberto às publicações científicas, e se estendem a elementos que ao ampliar seu escopo, pressupõem abertura ao conhecimento científico. 
A partir do levantamento e análise do percurso histórico das iniciativas de comunicação de dados de pesquisa bem como de documentos que estabelecem valores, direções e ações, é possível concluir que o incentivo à produção, compartilhamento e reutilização, inicia e vai muito além da questão da infraestrutura tecnológica necessária. O envolvimento de diferentes atores, tais como pesquisadores, instituições de pesquisa e universidades, agências de fomento e editores científicos, revela uma complexa rede de interesses distintos daqueles que envolvem as publicações científicas, e cujas intencionalidades necessitam ser acomodadas em suas diferentes dimensões. Essas dimensões referem-se às questões tecnológicas, gerenciais, comerciais, legais, culturais e políticas.

Um dos resultados deste trabalho foi a proposição de conjunto basilar de princípios e recomendações. A proposta baseia-se na essência de entendimentos declarados e até então existentes, e tem por objetivo não apenas sintetizar questões centrais, mas também servir de guia para a operacionalização de iniciativas.

\section{Referências}

ARCHAEOLOGY Data Service. Archaeology Data Service: homepage. York: University of York, [20--]. Disponível em:

$<$ http://archaeologydataservice.ac.uk/>. Acesso em: 6 out. 2016.

CORTI, L. et al. Managing and sharing research data: a guide to good practice. Los Angeles: SAGE, 2014.

COSTA, S. M. S. Filosofia aberta, modelos de negócios e agências de fomento: elementos essenciais a uma discussão sobre o acesso aberto à informação científica. Ciência da Informação, Brasília, v. 35, n. 2, p. 39-50, ago. 2006. Disponível em: $<$ http://revista.ibict.br/ciinf/article/view/1139/1294>. Acesso em: 7 dez. 2015.

DRYAD Digital Repository. Dryad Digital Repository (DRAYAD). Durham, 2016. Disponível em: <http://datadryad.org/>. Acesso em: 6 out. 2016. 
and-research-data-in-horizon-2020>. Acesso em: 7 dez. 2015.

EUROPEAN COMMISSION. H2020 Model Grant Agreements. 2015.

Disponível em:

$<$ http://ec.europa.eu/research/participants/data/ref/h2020/mga/gga/h2020-mgagga-mono en.pdf>. Acesso em: 7 dez. 2015.

FLÓRIA-SANTOS, M.; NASCIMENTO, L. C. Perspectivas históricas do Projeto Genoma e a evolução da enfermagem. Revista Brasileira de Enfermagem, Brasília, v. 59, n. 3, p. 358-361, maio/jun. 2006.

GARVEY, W. D. Communication: the essence of science. Oxford: Pergamon Press, 1979.

GUIBAULT, L.; WIEBE, A (Ed.). Safe to be open: study on the protection of research data and recommendations for access and usage. [S.1.]:

Universitätsverlag Göttingen, 2013.

HRYNASZKIEWICZ, I.; COCKERILL, M. J. Open by default: a proposed copyright license and waiver agreement for open access research and data in peer-reviewed journals. BMC Research Notes, [S.1.], v. 5, p. 494, 2012. Disponível em: <http://bmcresnotes.biomedcentral.com/articles/10.1186/17560500-5-494>. Acesso em: 7 dez. 2015.

MEDICAL Research Council, M. R. C. Data support service. Swindon, c2016. Disponível em: $<$ http://www.mrc.ac.uk/research/policies-and-resources-for-mrcresearchers/data-sharing/>. Acesso em: 6 out. 2016.

MOLLOY, J. C. The open knowledge foundation: open data means better science. PLoS Biology, [S.1.], v. 9, n. 12, p. 1-4, Dec. 2011. Disponível em: $<$ http://journals.plos.org/plosbiology/article?id=10.1371/journal.pbio.1001195>. Acesso em: 7 dez. 2015.

NATIONAL INSTITUTES OF HEALTH. NIH data sharing policy and implementation guidance. 2003. Disponível em: <http:/grants.nih.gov/grants/ policy/data_sharing/data_sharing_guidance.htm\#goals $>$. Acesso em: $7 \mathrm{dez}$. 2015.

NATURAL Environment Research Council. NERC. c2016. Disponível em: <www.nerc.ac.uk/>. Acesso em: 9 out. 2016.

OPEN KNOWLEDGE INTERNATIONAL. Open definition. [2016].

Disponível em: $<$ http://opendefinition.org/licenses/\#Data>. Acesso em: 5 out. 2016.

OPEN KNOWLEDGE FOUNDATION. Is it open data? [20--]. Disponível em: <http://www.isitopendata.org/>. Acesso em: 6 out. 2016. 
ORGANIZATION FOR ECONOMIC CO-OPERATION AND DEVELOPMENT. Declaration on access to research data from public funding. 2004. Disponível em:

$<\underline{\text { http://acts.oecd.org/Instruments/ShowInstrumentView.aspx? InstrumentID }=157}$ \# ftn>. Acesso em: 7 dez. 2015.

ORGANIZATION FOR ECONOMIC CO-OPERATION AND DEVELOPMENT. OECD principles and guidelines for access to research data from public funding. Paris, c2007. Disponível em: <http://www.oecd.org/dataoecd/9/61/38500813.pdf>. Acesso em: 7 dez. 2015.

PADILLA NAVARRO, P. A. et al. Acceso a datos de investigación e información científica en Chile. Revista española de Documentación Científica, Madrid, v. 36, n. 3, 2013. Disponível em:

$<$ http://redc.revistas.csic.es/index.php/redc/article/view/812/983>. Acesso em: 7 dez. 2015.

RAND, R. Y. The Global Change Data and Information System-Assisted Search for Knowledge (GC-ASK) project. D-Lib Magazine, Aug. 1995. Disponível em: < http://www.dlib.org/dlib/august95/08rand.html>. Acesso em: 7 dez. 2015.

RESEARCH COUNCILS UK. RCUK ambition. c2014. Disponível em:

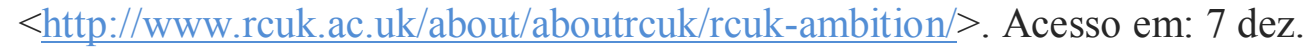
2015.

RIBEIRO, C. et al. Os repositórios da dados científicos: estado da arte. Versão 1.0. [S.1.: s.n.], 2010. Disponível em: $<$ http://repositorioaberto.up.pt/handle/10216/23806>. Acesso em: 30 mar. 2016.

RUTTENBERG, S.; RISHBETH, H. World data centres: past, present and future. Journal of Atmospheric and Terrestrial Physics, Oxford, v. 56, n. 7, p. 865-870, May 1994.

SCIENCE Commons. Protocol for implementing open access data. [20--]. Disponível em: <http://sciencecommons.org/projects/publishing/open-accessdata-protocol/>. Acesso em: 6 out. 2016.

SCIENTIFIC Computing Department. Scientific data. Chesire: Science and Technology Facilities Council, c2016. Disponível em:

<http://www.scd.stfc.ac.uk/SCD/support/43928.aspx>. Acesso em: 6 out. 2016.

SØNDERGAARD, T. F. et al. Documents and the communication of scientific and scholarly information: revising and updating the UNISIST model. Journal of Documentation, [S.1.], v. 59, n. 3, p. 278-320, 2003.

STATEMENT on Data Sharing in Public Health Emergencies. 2016. Disponível em: <http://blogs.plos.org/plos/2016/02/statement-on-data-sharing-in-publichealth-emergencies/>. Acesso em: 10 mar. 2016. 
UK Data Service. About UK data service. Essex, c2016. Disponível em: $<$ https://www.ukdataservice.ac.uk/>. Acesso em: 6 out. 2016.

UNITED NATIONS EDUCATIONAL, SCIENTIFIC AND CULTURAL ORGANIZATION. UNISIST: study report on the feasibility of a world science information system. Paris, 1971.

WORLD Data System. Data and services. Tokyo, [20--]. Disponível em: $<$ https://www.icsu-wds.org/services/data-portal>. Acesso em: 6 out. 2016.

ZATZ, M. Projeto genoma humano e ética. São Paulo em Perspectiva, São Paulo, v. 14, n. 3, p. 47-52, jul. 2000.

\title{
Principles and basic recommendations for the research data communication
}

\begin{abstract}
The communication of research data - it involves aspects of production, sharing and reuse of research data - has been intensified in the apex of the emergence open science's paradigm. In this context, several principles and recommendations emerged to guide the discussions and the practices. The aim of this paper is to propose fundamental set of principles and recommendations for the research data communication through the identification and analysis of the historical development of practices and policies that have guided the discussion and initiatives about research data communication. It was adopted as methods literature and documentary research. The first was the historical narrative of events, based on a timeline. The second was the comparative analysis of principles and statements identified by literature and document research. Among the results, it was possible to propose a set of principles and basic recommendations for communication research data.
\end{abstract}

Keywords: Data sharing. Open data. Research data.

Recebido: 20/06/2016

Aceito: 16/08/2016

\footnotetext{
${ }^{1}$ Dados de dezembro de 2015.
} 
${ }^{2}$ O RCUK é uma organização que reúne sete conselhos de pesquisa do Reino Unido e segundo seus dados, investem 3 bilhões de libras em pesquisa por ano (RESEARCH COUNCILS UK, 2014).

${ }^{3}$ Os requisitos para o compartilhamento e reuso de dados no documento são apresentados no item 29.3 .

${ }^{4}$ Os números do losango indicam o ano exato em que a iniciativa ou documento foram lançados.

${ }^{5}$ A sigla PP foi refere-se ao documento Panton Principles e foi utilizada apenas no quadro 10 deste trabalho. 